\title{
Health related quality of life after conservative or invasive treatment of inducible postinfarction ischaemia
}

O S Mortensen, J K Madsen, T Haghfelt, P Grande, K Saunamäki, S Haunsø, E Hjelms, $\mathrm{H}$ Arendrup, on behalf of the DANAMI study group

\begin{abstract}
Objective-To assess health related quality of life in patients with inducible postinfarction ischaemia.

Design-A questionnaire based follow up study on patients randomised to conservative or invasive treatment because of postinfarction ischaemia.

Setting-Seven county hospitals in eastern Denmark and the Heart Centre, National University Hospital, Copenhagen, Denmark.

Patients-113 patients with inducible postinfarction ischaemia: 51 were randomised to conservative treatment and 62 to invasive treatment. Average follow up time was three years (19-57 months).

Main outcome measures-SF-36, Rose angina and dyspnoea questionnaire, drug use, lifestyle, and cognitive function.

Results-Invasively treated patients scored better on the SF-36 scales of physical functioning $(p=0.03)$ and on role-physical $(p=0.04)$ and physical component scales $(p=0.05)$ and took significantly less anti-ischaemic drug treatment. Angina occurred in $18 \%$ of the invasively treated patients and $31 \%$ of the conservatively treated patients $(p=0.09)$. However, more invasively treated patients suffered from concentration difficulties $(18 \% v 4 \% ; \mathrm{p}=0.04)$.

Conclusions-Patients who were treated invasively had better health related quality of life scores in the physical variables compared with conservatively treated patients. However, a larger proportion of invasively treated patients had concentration difficulties.

(Heart 2000;84:535-540)
\end{abstract}

Keywords: SF-36; health related quality of life; postinfarction ischaemia

How should we treat patients with inducible postinfarction ischaemia following thrombolytic treatment for acute myocardial infarction? Several studies have shown no differences between invasive and medical treatment of these patients in terms of mortality or cardiovascular events when the invasive treatment was carried out shortly after the thrombolysis. ${ }^{1-5}$

An invasive strategy resulted in significant reduction of the primary end point (death, reinfarction, admission for unstable angina) compared with conservative treatment during 2.4 year follow up in patients with inducible ischaemia in the recently published DANAMI study (the Danish trial in acute myocardial infarction). ${ }^{6}$ These patients had a low mortality and there was no significant difference between the groups for mortality alone. Therefore self assessed symptoms, health status, and quality of life are important end points for evaluation of treatment of patients with inducible postinfarction ischaemia. Evaluations of health related quality of life are especially important in studies where small or no differences are found in mortality. ${ }^{7}$

In this study we compare the health related quality of life of 113 patients who took part in the DANAMI study during the period 1990 to 1994 and were randomised to either medical or invasive treatment. The focus was on health related quality of life as measured by self reported information on health, symptoms, and drug consumption, as well as information on functional capacity in daily routines, including social, intellectual, emotional, and financial dimensions.

\section{Methods}

PATIENT SELECTION AND STUDY PROTOCOL The DANAMI study included 1008 patients under the age of 70 years with first time acute myocardial infarction for which thrombolytic treatment had been given within 12 hours of the onset of symptoms, and who on discharge had inducible postinfarction ischaemia. The patients were then randomised to either invasive treatment (coronary arteriography followed by percutaneous transluminal coronary angioplasty (PTCA) or coronary artery bypass graft (CABG), if indicated) or conservative treatment. ${ }^{6}$ Of these 1008 patients, 122 were included in this study. They did not differ from the patients in the parent study with respect to age, sex, or prevalence of diabetes. All patients were randomised in two counties in eastern Denmark, and those who were randomised to the invasive strategy were treated at the same cardiological centre.

In all, 56 patients were randomised to conservative treatment. Of these, 12 subsequently underwent invasive treatment (six PTCA and six bypass) owing to unacceptable angina. Of the 66 patients who were 
randomised to invasive treatment, 18 underwent a bypass operation, 38 received PTCA treatment, two underwent both PTCA and a bypass operation, and eight received no invasive intervention following coronary angiography. Patients who received bypass surgery were given no further invasive treatment. Five PTCA patients received further invasive treatment (three bypass and two re-PTCA), and one patient who originally did not receive invasive treatment has since undergone bypass surgery.

The study was carried out as a follow up study, using questionnaires sent by mail. Of the 122 patients, 119 were alive at the time of the present study. Two of the deceased were in the invasive group and the third was in the conservative treatment group. Two additional patients were lost to follow up. All 117 patients were contacted by telephone to inform them of the purpose of the study and to allow them an opportunity to comment on their treatment and to say what had been of special importance to them during the course of the illness and its treatment. The consent of each patient was then obtained before forwarding a questionnaire. In all, 114 patients $(97.4 \%)$ completed and returned the questionnaire; one questionnaire was not used in the data analysis owing to low data quality. Five reminders were send. The average follow up time was three years.

\section{MEASUREMENT}

The components of the questionnaire are based on recommendations from 1985 established by Wenger and colleagues relating to the assessment of health related quality of life in cardiovascular studies. ${ }^{8}$ These recommendations have since become the gold standard and include functional capacity (daily routine, social function, intellectual function, emotional function, and economic aspects), perceptions (health status, wellbeing, and life satisfaction), and symptoms (heart related, and symptoms from other illnesses). In addition, questions on lifestyle, diet, and the use of drugs were included.

\section{Short form 36}

Short form 36 (SF-36) is a generic questionnaire consisting of 36 questions covering eight aspects of health status: physical functioning, role-physical (role limitations because of physical health problems), bodily pain, general health, vitality, social functioning, roleemotional (role limitations because of emotional problems), and mental health. ${ }^{9-11}$ Thus in addition to health status, SF-36 covers three of the subcomponents of functional capacity: daily routines, social capacity, and emotional capacity. The questions relating to each area are summed and rescaled to a 100 point scale, where 100 is the best possible score and zero the worst possible. The eight scales in SF-36 can be further aggregated into two component scales: one for physical components and the other for mental components. ${ }^{12}$

The scoring of SF-36 data was carried out as described by Ware and colleagues. ${ }^{13}$ There are established guidelines concerning clinically relevant differences for the SF-36 scores ${ }^{13}$; however, in this study, modified guidelines were followed. Differences in the individual subscales of 10 points or more were considered clinically relevant, while differences of 5-10 points may be clinically relevant although there can be an element of uncertainty. Differences of less than five points were not considered clinically relevant. These assumptions concerning clinically relevant levels are based on analyses of differences between patients with different chronic illnesses and a background population, ${ }^{13} 14$ and exceed the recommendations from the SF-36 manual.

The interpretation of the summary scales is more complex, but owing to the large number of measurement points the summary scales have high precision. We considered differences of three points or more to be clinically relevant. This is higher than the recommendation in the summary scale interpretation guidelines. ${ }^{12}$

Reliability and validity studies have been carried out for the SF-36 in Denmark among the general population, and the Danish translation of SF-36 has been validated. ${ }^{15} 16$ These data are presented in table 2 for comparison purposes. In the patient population in this study, the SF-36 subscales were found to be reliable. Cronbach- $\alpha$ analyses of the eight subscales showed values from 0.77 on the general health scale to 0.93 on the scale measuring physical limitations in everyday routines.

\section{Physical and cognitive symptoms}

The illness specific symptoms measured in this study were angina pectoris and dyspnoea. A modified version of Rose's angina questionnaire was used to evaluate angina pectoris, which focused on symptoms during the preceding four weeks and not on whether the patients had ever had symptoms. The questionnaire allowed for a three level grading of angina pectoris. ${ }^{17}$ Dyspnoea was measured according to the Rose dyspnoea questionnaire, which grades dyspnoea on a four point scale, ranging from no dyspnoea to dyspnoea during daily routines. ${ }^{18}$ As an extra surrogate indicator of illness-specific symptoms, drug consumption was also recorded.

Financial functional capacity was measured on the basis of employment status. Intellectual functional capacity was measured by questions concerning concentration abilities and memory; these questions were previously used as screening questions in Danish population studies. ${ }^{19}$ Problems associated with sleep were also queried. ${ }^{19}$

\section{Lifestyle}

Smoking habits reflected whether patients were smokers, ex-smokers, or had never smoked, and whether in the case of smokers they had attempted to give up the habit. ${ }^{14}$ Leisure time physical activities were measured in terms of the number of hours devoted to light or strenuous physical activity. ${ }^{14}$ The patients' own evaluations of their physical fitness were measured on a scale ranging from "excellent" to "poor". 
Table 1 Characteristics of the study population by treatment group

\begin{tabular}{llll}
\hline & Conservative & Invasive & p Value \\
\hline Number of patients & 56 & 66 & \\
Age (years) (mean and range) & $59.8(38$ to 72$)$ & $59.5(36$ to 72$)$ & NS \\
Male patients (\%) & 78.8 & 81.8 & NS \\
Follow up period (months) (mean and range) & $36.4(21$ to 56$)$ & $37.2(19$ to 57$)$ & NS \\
Diabetes mellitus (\%) & 8.9 & 6.1 & NS \\
\hline
\end{tabular}

\section{Pilot study}

The questionnaire was tested in a pilot study designed to evaluate empirically the scale structures and test the validity of content and terminology. The pilot test included 33 patients who answered questionnaires and in depth qualitative interviews with five patients. The development of the questionnaire and issues concerning its reliability and validity are described in detail elsewhere. ${ }^{20}$

\section{HYPOTHESES AND STATISTICAL METHODS}

The most significant effects of invasive treatment were expected to be related to physical functioning. Consequently, the main hypothesis was that a difference would show up between the treatment groups in the physical component scale of SF-36. As a supplementary descriptive analysis, the differences between all eight SF-36 subscales were evaluated. These results are reported as mean values and standard deviations, in line with the standard approach for reporting SF-36 data. As the distributions of the SF-36 scales were skewed, Wilcoxon's non-parametric test was used for group comparisons. Comparisons for other variables were tested using the $\chi^{2}$ test.

All primary analyses were carried out in accordance with the "intention to treat" principle. Several patients had not followed the treatment strategy, as indicated by the randomisation process, and therefore the SF-36 and symptom data were also subjected to censored analysis. These supplementary analyses cast light on the health related quality of life of patients for whom it was necessary to perform invasive intervention not foreseen at the start of the study. The patients were included in the study over a four year period. Supplementary analyses were made taking the time perspective into account.

ETHICS

After receiving both verbal and written information on the purpose of the study, all patients taking part gave their consent. The study was approved by the scientific ethics committee for

Table 2 Short form 36 (SF-36) subscales and component scores for the two treatment groups, with age matched normative scores included for comparison *

\begin{tabular}{lllll}
\hline & $\begin{array}{l}\text { Conservative } \\
(n=51)\end{array}$ & Invasive $(n=62)$ & $p$ Value & $\begin{array}{l}\text { National norms } \\
(n=2183)\end{array}$ \\
\hline Physical functioning & $78.3(17.3), \mathrm{n}=50$ & $82.4(20.7), \mathrm{n}=60$ & 0.03 & $85.9(20.8)$ \\
Role-physical & $55.3(44.3), \mathrm{n}=50$ & $69.4(42.3), \mathrm{n}=58$ & 0.04 & $80.8(33.3)$ \\
Bodily pain & $78.6(21.3), \mathrm{n}=51$ & $83.4(22.9), \mathrm{n}=59$ & 0.13 & $77.8(24.2)$ \\
General health & $66.7(19.6), \mathrm{n}=49$ & $66.1(22.0), \mathrm{n}=59$ & 0.99 & $73.4(20.9)$ \\
Vitality & $66.3(21.2), \mathrm{n}=51$ & $67.6(23.8), \mathrm{n}=61$ & 0.62 & $69.8(21.0)$ \\
Social functioning & $90.7(16.0), \mathrm{n}=51$ & $88.7(22.5), \mathrm{n}=62$ & 0.99 & $90.6(18.5)$ \\
Role-emotional & $73.5(35.3), \mathrm{n}=49$ & $74.3(38.8), \mathrm{n}=57$ & 0.67 & $86.2(28.1)$ \\
Mental health & $82.8(17.9), \mathrm{n}=51$ & $80.2(17.5), \mathrm{n}=61$ & 0.32 & $81.8(16.5)$ \\
Physical component score & $45.4(9.7), \mathrm{n}=47$ & $48.5(9.6), \mathrm{n}=55$ & 0.05 & $50.1(9.4)$ \\
Mental component score & $54.2(9.6), \mathrm{n}=47$ & $52.6(9.4), \mathrm{n}=55$ & 0.30 & $54.2(8.7)$ \\
\hline
\end{tabular}

${ }^{\star}$ National norms from general population aged 36 to 72 years. ${ }^{14}$

Values are mean (SD). the Danish counties of Bornholm, Frederiksborg, Roskilde, Storstrøm, and Vestsjælland, J.no.:1994-2-29, and is in accordance with the provisions of the Helsinki declaration.

\section{Results}

BASELINE CHARACTERISTICS

Table 1 shows that the two randomisation groups in this study were comparable with respect to sex, age, follow up time, and history of diabetes mellitus. The patients were included in the DANAMI study 1991-1994, the questionnaires were send to the patients in October 1995.

SF-36 SCALES FOR THE TOTAL POPULATION

Table 2 shows the results for the various SF-36 scales. Those patients randomised to invasive treatment had higher scores than those randomised to medical treatment for the physical component scale $(p=0.05)$ and for the two physical subscales: physical functioning $(\mathrm{p}=0.03)$ and role-physical $(\mathrm{p}=0.04)$. No consistent differences were seen in the mental component scale of SF-36 and the subscales related to general and mental health. Both groups of patients had scores that were fairly close to national norms for most scales. The notable exceptions were the role-physical and role-emotional subscales, for which these patients scored much lower than the general population.

\section{PER PROTOCOL ANALYSIS}

Table 3 shows results from the censored analyses. When restricted to those who followed the intended treatment strategy, the pattern of differences between treatment groups was similar, although the magnitude was somewhat reduced. While differences remained between the treatment groups in the SF-36 "physical functioning" subscale $(\mathrm{p}=0.04)$, there was no longer significant differences in the "rolephysical" subscale $(p=0.11)$. Censored analysis of the physical component score showed a non-significant advantage in terms of invasive treatment $(p=0.06)$. A higher mental component score was found among medically treated patients $(p=0.03)$.

\section{CLINICAL SYMPTOMS AND MEDICATION}

Table 4 shows results for the physical and cognitive symptoms and drug use. There was no significant difference in the prevalence of anginal symptoms between the groups but significantly more conservatively treated than invasively treated patients took antianginal drugs.

More patients had difficulties in concentrating in the invasive group than in the conservative group $(18.3 \%$ v $3.9 \% ; \mathrm{p}=0.04)$. The prevalence of concentration problems was the same in the angioplasty group and the CABG group. None of the PTCA treated patients who claimed to have difficulties in concentration had undergone bypass surgery since randomisation. Patients who had had invasive treatment and who reported cognitive problems had lower scores in all eight SF-36 subscales than those who did not report cognitive problems: physical function, 88.1 v $68.0(\mathrm{p}<0.001)$; 
Table 3 Censored analysis of short form 36 (SF-36) subscales, component scores, and symptom data groups based on actual treatment

\begin{tabular}{|c|c|c|c|c|c|c|}
\hline & $\begin{array}{l}\text { Conservative } \\
(n=39)\end{array}$ & $\begin{array}{l}\text { Invasive } \\
(n=49)\end{array}$ & $p$ Value & $\begin{array}{l}\text { Conservative } \\
\text { crossover }(n=12)\end{array}$ & $\begin{array}{l}\text { Invasive } \\
\text { retreated }(n=6)\end{array}$ & $\begin{array}{l}\text { Invasive, } \\
\text { no treatment }(n=7)\end{array}$ \\
\hline Physical functioning & $78.4(18.0)$ & $84.1(18.1)$ & 0.04 & $77.9(15.6)$ & $74.2(28.0)$ & $77.8(30.5)$ \\
\hline Role-physical & $59.2(43.7)$ & $70.1(42.4)$ & 0.11 & $43.1(46.2)$ & $50.0(47.4)$ & $83.3(40.8)$ \\
\hline Bodily pain & $79.1(22.6)$ & $83.6(22.8)$ & 0.27 & $76.8(17.1)$ & $83.0(26.0)$ & $82.4(25.4)$ \\
\hline General health & $67.2(18.6)$ & $66.5(21.6)$ & 0.95 & $64.8(23.1)$ & $68.6(26.5)$ & $61.4(24.8)$ \\
\hline Vitality & $69.1(21.4)$ & $67.9(22.5)$ & 0.88 & $57.5(18.6)$ & $60.0(34.8)$ & $72.1(24.8)$ \\
\hline Social functioning & $91.3(16.0)$ & $91.3(18.1)$ & 0.96 & $88.5(16.4)$ & $70.8(40.1)$ & $85.7(28.3)$ \\
\hline Role-emotional & $80.2(28.8)$ & $76.3(37.4)$ & 0.97 & $52.8(46.0)$ & $50.0(45.9)$ & $83.3(40.8)$ \\
\hline Mental health & $86.1(15.1)$ & $81.6(16.1)$ & 0.11 & $72.3(22.8)$ & $72.0(23.0)$ & $77.7(22.1)$ \\
\hline MCS & $56.3(7.8)$ & $53.0(8.1)$ & 0.03 & $47.8(11.8)$ & $47.0(16.0)$ & $54.2(12.1)$ \\
\hline PCS & $45.2(9.9)$ & $48.6(9.6)$ & 0.06 & $46.0(9.3)$ & $49.3(10.3)$ & $47.4(11.2)$ \\
\hline Angina pectoris & $30.8 \%$ & $14.3 \%$ & 0.06 & $33.3 \%$ & $33.3 \%$ & $28.6 \%$ \\
\hline
\end{tabular}

Values are mean (SD).

MCS, mental component score; PCS, physical component score.

role-physical, $84.8 v 32.4$ ( $\mathrm{p}<0.0001)$; bodily pain, $91.8 v 60.8(\mathrm{p}<0.0001)$; general health, 74.4 v 43.9 ( $\mathrm{p}<0.0001$ ); vitality, 75.6 v 48.6 $(\mathrm{p}<0.001)$; social function, $95.2 \vee 72.9$ $(\mathrm{p}<0.0001) ;$ role-emotional, 88.3 v 41.2 $(\mathrm{p}<0.0001)$; and mental health, 85.6 67.3 $(\mathrm{p}<0.001)$. Patients in the medically treated group who reported cognitive problems had lower SF-36 scores for physical function than those who did not report cognitive problems (81.6 $v 63.3, \mathrm{p}=0.03)$; subscale analysis: rolephysical, 60.8 v $30.6 \quad(\mathrm{p}=0.05)$; general health, $70.4 v 50.2(\mathrm{p}=0.01)$; vitality, $70.4 v$ 47.2 ( $\mathrm{p}<0.01$ ); social functioning, $93.2 v 79.2$ $(\mathrm{p}=0.01) ;$ and role-emotional, $78.3 \approx 51.9$ $(\mathrm{p}<0.05)$.

TIME RESTRICTED ANALYSIS

Table 5 shows results for the SF-36 subscales, cognitive function, and presence of angina analysed for the inclusion period 1991-92 and

Table 4 Clinical symptoms and drug treatment for the two treatment groups

\begin{tabular}{lllr}
\hline & $\begin{array}{l}\text { Conservative } \\
(n=51)(\%)\end{array}$ & $\begin{array}{l}\text { Invasive } \\
(n=62)(\%)\end{array}$ & $p$ Value \\
\hline Angina pectoris & 31.4 & 17.7 & 0.09 \\
Medium or severe dyspnoea & 17.6 & 22.6 & 0.52 \\
Long acting nitrates & 33.3 & 11.3 & $<0.01$ \\
$\beta$ Blockers & 37.3 & 12.9 & $<0.01$ \\
Calcium antagonists & 47.1 & 29.0 & $<0.05$ \\
Diuretics & 29.4 & 17.7 & 0.14 \\
ACE inhibitors & 21.6 & 19.4 & 0.77 \\
Difficulty in concentrating & 3.9 & 18.3 & 0.04 \\
Memory lapses & 17.7 & 24.6 & 0.65 \\
No cognitive problems & 82.4 & 70.9 & 0.15 \\
Both concentration and memory problems & 3.9 & 12.9 & 0.08 \\
\hline
\end{tabular}

ACE, angiotensin converting enzyme.

Table 5 SF-36 subscales and component scores, angina pectoris, and cognitive functions in the two treatment groups. Groups based on time for randomisation

\begin{tabular}{|c|c|c|c|c|c|c|}
\hline & $\begin{array}{l}\text { Conservative } \\
\text { randomised 1991-92 }\end{array}$ & $\begin{array}{l}\text { Invasive randomised } \\
1991-92\end{array}$ & p Value & $\begin{array}{l}\text { Conservative } \\
\text { randomised 1993-94 }\end{array}$ & $\begin{array}{l}\text { Invasive randomised } \\
\text { 1993-94 }\end{array}$ & $p$ Value \\
\hline Number of patients & 25 & 31 & & 26 & 31 & \\
\hline Average follow up (range in months) & $44.3 \quad(36-56)$ & $45.5 \quad(36-57)$ & 0.45 & $28.7 \quad(21-35)$ & $28.9(19-35)$ & 0.89 \\
\hline Physical functioning & $77.2 \quad(15.5)$ & $78.1 \quad(24.0)$ & 0.26 & $79.4 \quad(19.2)$ & $86.9 \quad(15.5)$ & 0.09 \\
\hline Role-physical & $47.7 \quad(42.5)$ & $67.7(44.8)$ & 0.06 & $63.0 \quad(45.7)$ & $71.3(40.8)$ & 0.37 \\
\hline Bodily pain & $76.4 \quad(23.2)$ & $79.3 \quad(25.4)$ & 0.59 & $80.7 \quad(19.6)$ & $87.3(19.9)$ & 0.12 \\
\hline General health & $64.4(21.8)$ & $64.4 \quad(21.0)$ & 0.94 & $68.8(17.4)$ & $67.8 \quad(23.3)$ & 0.75 \\
\hline Vitality & $64.6 \quad(18.6)$ & $67.3(24.6)$ & 0.54 & $68.0 \quad(23.7)$ & $67.9 \quad(23.5)$ & 0.99 \\
\hline Social functioning & $87.5 \quad(17.3)$ & $86.3(21.0)$ & 0.95 & $93.8 \quad(14.3)$ & $91.1 \quad(24.0)$ & 0.99 \\
\hline Role-emotional & $65.3(38.7)$ & $67.8 \quad(42.4)$ & 0.66 & $81.3(30.6)$ & $81.5 \quad(33.8)$ & 0.83 \\
\hline Mental health & $79.0 \quad(20.2)$ & $79.7 \quad(18.8)$ & 0.91 & $86.5 \quad(15.0)$ & $80.6(16.5)$ & 0.11 \\
\hline PCS & $44.8 \quad(10.1)$ & $47.2 \quad(10.1)$ & 0.33 & $46.0(9.4)$ & $50.0 \quad(9.1)$ & 0.06 \\
\hline MCS & $52.4 \quad(10.9)$ & $52.2(9.5)$ & 0.81 & $55.8(8.0)$ & $53.1 \quad(9.5)$ & 0.20 \\
\hline Angina pectoris & $32.0 \%$ & $25.8 \%$ & 0.61 & $30.8 \%$ & $9.7 \%$ & 0.04 \\
\hline Difficulty in concentration & $4.0 \%$ & $22.6 \%$ & 0.04 & $3.9 \%$ & $12.9 \%$ & 0.21 \\
\hline Memory lapses & $16.0 \%$ & $29.0 \%$ & 0.24 & $19.2 \%$ & $19.4 \%$ & 0.99 \\
\hline Both concentration and memory problems & $4.0 \%$ & $19.4 \%$ & 0.07 & $3.9 \%$ & $6.5 \%$ & 0.65 \\
\hline
\end{tabular}

Values are mean (SD)

MCS, mental component score; PCS, physical component score. for 1993-94. The trend in favour of invasive treatment was found in the physical subscales of the SF-36 in both inclusion periods. Patients randomised to invasive treatment in 1993-94 had significantly less angina than patients randomised to conservative treatment $(p=0.04)$. No difference was found for patients randomised in 1991-92.

LIFESTYLE AND RETURN TO WORK

With regard to smoking habits, no differences were found between the two groups, as $41.2 \%$ of the conservative patients and $45.2 \%$ of the invasive patients remained smokers. There were no differences between the treatment groups with regard to health related sexual problems (conservative 30.6\%, invasive $28.8 \%$ ), leisure time physical activity (more than four hours hard exercise a week: conservative $37.0 \%$, invasive $39.3 \%$ ), self evaluated fitness ("good" or "very good": conservative $47.1 \%$, invasive $51.7 \%$ ), or return to work (conservative $34.0 \%$, invasive $31.2 \%$ ).

\section{Discussion}

The invasively treated patient group revealed significantly higher scores in the SF-36 physical scales, a lower consumption of antianginal drugs, and fewer heart related symptoms compared with the medically treated patient group.

Within this patient population, the health related quality of life of those with postinfarction ischaemia following thrombolytic treatment for myocardial infarction was generally good, and several SF-36 subscales showed 
results equal to those of a comparable background population. However, significantly more patients in the invasive treatment group reported difficulties in concentration.

The high SF-36 scores in both treatment groups are in accordance with other studies of patients who have received thrombolytic treatment for acute myocardial infarction. ${ }^{21-23}$ However, we observed that in comparison with the conservative treatment strategy, invasive treatment for patients with postinfarction ischaemia improves both their physical functional ability and their subjective feeling of having the capacity to carry out physical activity. The difference in the role-physical subscale was 14.1 points, which must be considered clinically relevant, whereas the 4.1 point difference in the physical functioning subscale cannot with certainty be considered clinically relevant, although the difference was significant. The difference in the physical component summary scale was 3.1 points, which must be considered clinically relevant.

The SF-36 scores in this study were significantly better than those in a more chronic patient population studied using the same questionnaire. ${ }^{20}$ This indicates that patients with their first acute myocardial infarction who undergo thrombolytic treatment within 12 hours have a significantly better prognosis for maintaining a good quality of life than patients with a more protracted and chronic illness.

Among patients who followed the planned treatment strategy, the censored analysis revealed that the ones randomised to invasive treatment had fewer physical symptoms and limitations than those randomised to conservative treatment, whereas the patients randomised to conservative treatment had fewer psychological symptoms and limitations than those randomised to invasive treatment. This suggests that invasive treatment can have a negative effect on the mental condition of some patients. This hypothesis is in line with other studies of patients with ischaemic heart problems, which showed that approximately $20 \%$ of patients referred for invasive treatment experienced poorer health related quality of life after the treatment than before the treatment. ${ }^{2024}$

The reduction in the use of antianginal drugs and in anginal symptoms in the invasive group appears very convincing. This finding contradicts the result from the SWIFT (should we intervene following thrombolysis?) study, ${ }^{2}$ but is in line with earlier studies showing that invasive treatment of patients with chronic ischaemic heart disease results in significant relief of symptoms and reduced consumption of antianginal drugs compared with medically treated patients. ${ }^{25-27}$ The questionnaire based data are thus consistent with data collected by doctors during the clinical controls in the DANAMI study with regard to angina and drug consumption. ${ }^{6}$

Our study had an average follow up period of 36 months, suggesting that the benefits of early invasive treatment in patients with postinfarction ischaemia last for a considerable time. This finding suggests that relieving anginal symptoms shortly after acute myocardial infarction has a long term benefit on physical functioning, maybe because it diminishes the risk of developing "sick role" behaviour. Approximately $20 \%$ of patients from the medical treatment group have received invasive treatment since randomisation, and we expect this will have improved their physical functioning ability.

In our study there were increased numbers of patients with concentration difficulties and memory lapses in the invasively treated group. This was found both in patients who underwent bypass surgery and in those treated by angioplasty. Neurological side effects are well documented after CABG. The symptoms usually resolve within six months. ${ }^{28}{ }^{29}$ However, some of our patients still had complaints after an average follow up of 36 months. Impaired mental function after PTCA has not been reported previously owing to a lack of adequate studies. Within the given design framework, one can only speculate as to the mechanism behind these problems. As the only factor in common for the two invasive groups was previous coronary arteriography, which is performed approximately four weeks after the myocardial infarct, a possible pathophysiological mechanism could be cerebral microemboli originating from aortic wall debris displaced during guided catheter movements. ${ }^{30}{ }^{31}$ By their nature, questionnaire based evaluations of cognitive function entail a degree of uncertainty, and the questions used in this study may be too crude for this evaluation. The ideal solution would be neuropsychological testing of these patients to verify the findings. ${ }^{29} 32$

The intention to treat analysis reveals no differences in the SF-36 mental and social subscales, despite significant differences in the physical subscales. This may reflect the fact that the SF-36 scores in the psychological and social subscales are higher in both patient groups than in the background population, and that consequently no major differences should be expected in these scales. The development of SF-36 is based on the theory that there is not necessarily any connection between the physical and the psychological subscales. ${ }^{33}$ Furthermore, it is precisely the social and emotional variables that have the best chance of responding to a regular rehabilitation programme. The patients underwent a clinical in-hospital follow up appointment after three, six, and 12 months, but none of the participants in this study had undergone a special heart rehabilitation programme. One possible consequence of the lack of rehabilitation is the disappointingly high proportion of patients in both treatment groups who continued to smoke. That over $40 \%$ of patients still smoke is, in an international context, a very disappointing result. ${ }^{25}$ It has previously been shown that giving up smoking is a significant factor in the prognosis of patients who have had a myocardial infarct, ${ }^{34}$ as well as among patients who have undergone revascularisation treatment. ${ }^{35}$ There is a greater risk of reinfarction and death among patients who continue to smoke than in those who discontinue smoking. As with earlier studies, it 
was found that invasive treatment did not make any difference to the proportion of patients who continued to work. ${ }^{36}$

\section{LIMITATIONS}

The study population was relatively small, and generalisation of the results should be done with caution. We do not have baseline quality of life data; therefore it is not possible to draw conclusions about causality from the results. The study is, on the other hand, strong in its randomised design, with a limited crossover between the groups, a long follow up period, and an excellent response rate. The questionnaire used in the study is based on well validated instruments, and the reliability and validity of the study questionnaire is well documented.

\section{CONCLUSIONS}

By following an invasive treatment strategy for patients with inducible postinfarction ischaemia, a better health related quality of life can be achieved than if a conservative treatment strategy is followed. The invasive strategy enables patients to attain improved physical functioning, fewer physically related limitations in daily routines, fewer symptoms, and reduced use of antianginal drugs. In this study we found no worsening of the patients' social functional ability or psychological symptoms compared with the general population, nor was any difference noted between the treatment groups. However, significantly more concentration difficulties were reported in the invasive group. These problems were divided equally between PTCA and bypass treated patients. Additional studies aimed at clarifying this finding are planned.

We want to thank Professor Beth Newman, Professor Brian Oldenburg, and Professor Finn Gyntelberg for valuable comments on previous drafts of this paper. Grants for the study were provided by the Danish Heart Foundation, Bob and Beb Tegners foundation, Johannes Kleins and wife's Foundation, The Thorvald Madsen Foundation, Mogens og Else WedellWedellsborg's Foundation, The Herluf Trolle Foundation, and the Emmerik Meyers Foundation. The DANAMI study was supported by the Danish Heart Foundation.

The patients were randomised at the following participating centres: Nykøbing Falster Centralsygehus $(n=25)$ (Bjarne Sigurd, Helle Nielsen, and John Hilskov); Ringsted Sygehus $(n=25)$ (Jens Erik Clausen, Kim Melbye, Jimmi Schultz, Peter Madsen, and Kern Olofsson); Holbæk Central Sygehus $(\mathrm{n}=24)$ (Erling Birk Madsen, Mogens Westergaard, and Dan Hansen); Næstved Central Sygehus $(\mathrm{n}=24)$ (Tage Lysbro Svendsen, Henrik Madsen, John Larsen, and Walther Nielsen); Svendsen, Henrik Madsen, John Larsen, and Walther Nielsen);
Nakskov Sygehus $(\mathrm{n}=11$ ) (Jørn Badskær and Tommy Budek); Nakskov Sygehus $(\mathrm{n}=11)$ (Jørn Badskær and Tommy Budek);
Slagelse Sygehus $(\mathrm{n}=9)$ (Per Eliasen); Fakse Amtssygehus Slagelse Sygehus $(n=9)$ (Per Eliasen); Fakse Amtssygehus
$(n=4)$ (Klaus Kølendorf). Patients randomised to invasive $(\mathrm{n}=4)$ (Klaus Kølendorf). Patients randomised to invasive
treatment were all treated at the Heart Centre, Rigshospitalet, treatment were all treated at the Heart Centre, Rigshospitalet, National University Hospital, Copenhagen, Denmark $(n=66)$
(Jan Kyst Madsen, Peer Grande, Stig Haunsø, Kari Saunamäki, (Jan Kyst Madsen, Peer Grande, Stig Ha
Rolf Steffensen, and Henrik Arendrup).

1 Barbash GI, Roth A, Hod H, et al. Randomized controlled trial of late in-hospital angiography and angioplasty versus conservative management after treatment with recombinant tissue-type plasminogen activator in a

SWIFT (Should We Intervene Following Thrombolysis?) Trial Study Group. SWIFT trial of delayed elective intervention $v$ conservative treatment after thrombolysis with anistreplase in acute myocardial infarction. $B M F$ 1991;302:555-60.

3 Simoons ML, Arnold AE, Betriu A, et al. Thrombolysis with tissue plasminogen activator in acute myocardial infarction: no additional benefit from immediate percutaneous coronary angioplasty. Lancet 1988;i:197-203.

4 Michels KB, Yusuf S. Does PTCA in acute myocardial infarction affect mortality and reinfarction rates? A quantitative overview (meta-analysis) of the randomized clinical tive overview (meta-analysis) of

5 Topol EJ, Califf RM, George BS, et al. A randomized trial of immediate versus delayed elective angioplasty after intravenous tissue plasminogen activator in acute myocardial infarction. N Engl f Med 1987;317:581-8.
6 Madsen JK, Grande P, Saunamäki K, et al. The Danish multicentre randomised study of invasive vs conservative treatment in patients with inducible ischaemia following thrombolysis in acute myocardial infarction (DANAMI). Circulation 1997;96:748-55.

7 Spilker B, Spilker B, eds. Quality of life and pharmacoeconomics in clinical trials, 2nd ed. Pennsylvania: Lippincott-Raven, 1996.

8 Wenger NK, Mattson ME, Furberg CD, et al, eds. Assessment of quality of life in clinical trials of cardiovascular therapies. New York: Le Jacq, 1984:1.

9 McHorney CA, Ware JE, Lu JF, et al. The MOS 36-item short-form health survey (SF-36). III. Tests of data quality, scaling assumptions, and reliability across diverse patient groups. Med Care 1994;32:40-66.

10 McHorney CA, Ware JE, Raczek AE. The MOS 36-item short-form health survey (SF-36). II. Psychometric and clinical tests of validity in measuring physical and mental health constructs. Med Care 1993;31:247-63.

11 Ware JE, Sherbourne CD. The MOS 36-item short-form health survey (SF-36). I. Conceptual framework and item selection. Med Care 1992;30:473-83.

12 Ware JE, Kosinski M, Keller SD. SF-36 physical and mental health summary scales - a users manual. Boston: The Health Institute, 1994:1.

13 Ware JE. SF-36 health survey manual and interpretation guide. Boston: The Health Institute, New England Medical Center, 1993:1.

14 Kjøller M, Rasmussen NK, Keiding L. Health and disease in Denmark 1994. Copenhagen: Danish Institute for Clinical Epidemiology, 1995.

15 Bjorner JB, Damsgaard MT, Watt T, et al. Tests of data quality, scaling assumptions, and reliability of the Danish SF-36. F Clin Epidemiol 1998;51:1001-11.

16 Bjorner JB, Thunedborg K, Kristensen TS, et al. The Danish SF-36 health survey: translation and preliminary validity studies. $\mathcal{F}$ Clin Epidemiol 1998;51:991-9.

17 Rose G, McCartney P, Reid DD. Self-administration of a questionnaire on chest pain and intermittent claudication. Br f Prev Soc Med 1977;31:42-8.

18 Rose G, Blackburn H. Cardiovascular survey methods. (WHO monograph series No 56.) Geneva: WHO, 1968

19 Hagerup L, Eriksen M, Schroll M, et al. The Glostrup population studies. Collection of epidemiologic tables. Reference values for use in cardiovascular population studies. Scand F Soc Med 1981;20(suppl): 1-112.

20 Mortensen OS. Invasively treated ischemic heart disease, quality of life aspects. Copenhagen: University of Copenhagen, 1998. [PhD thesis.]

21 Glasziou PP, Bromwich S, Simes RJ. Quality of life six months after myocardial infarction treated with thrombolytic ther. AUS-TASK Group. Australian aro thromnational tPA/SK mortality trial. Med f Aust 1994;161:532-6.

22 Wiklund I, Herlitz J, Hjalmarson A. Quality of life five years after myocardial infarction. Eur Heart $\mathcal{F}$ 1989;10:464-72.

23 Brown N, Melville M, Gray D, et al. Quality of life four years after acute myocardial infarction: short form 36 scores compared with a normal population. Heart 1999;81:352-8.

24 Mayou R, Bryant B. Quality of life after coronary artery surgery. $Q \mathcal{F}$ Med 1987;62:239-48.

25 Rogers WJ, Coggin CJ, Gersh BJ, et al. Ten-year follow-up of quality of life in patients randomized to receive medical therapy or coronary artery bypass graft surgery. The coronary artery surgery study (CASS). Circulation 1990;82: 1647-58.

26 Peduzzi P, Hultgren $\mathrm{H}$, Thomsen J, et al. Ten-year effect of medical and surgical therapy on quality of life: Veterans Administration cooperative study of coronary artery surgery. Am $\mathcal{F}$ Cardiol 1987;59:1017-23.

27 Strauss WE, Fortin T, Hartigan P, et al. A comparison of quality of life scores in patients with angina pectoris after ngioplasty compared with after medical therapy. Outcomes of a randomized clinical trial. Veterans Affairs study of angioplasty compared to medical therapy investigators. Circulation 1995;92:1710-19.

28 Shaw PJ, Bates D, Cartlidge NE, et al. Early neurological complications of coronary artery bypass surgery. BMF $1985 ; 291: 1384-7$

29 Blumenthal JA, Mahanna EP, Madden DJ, et al. Methodological issues in the assessment of neuropsychologic function after cardiac surgery. Ann Thorac Surg 1995;59:1345-50.

30 Keeley EC, Grines CL. Scraping of aortic debris by coronary guiding catheters; a prospective evaluation of 1000 cases. f Am Coll Cardiol 1998;32:1861-5.

31 Brækken SK, Endresen K, Russell D, et al. Influence of guidewire and catheter type on the frequency of cerebral microembolic signals during left heart catherization. $A m \mathcal{F}$ Cardiol 1998;82:632-7.

32 Mahanna EP, Blumenthal JA, White WD, et al. Defining neuropsychological dysfunction after coronary artery bypass grafting. Ann Thorac Surg 1996;61:1342-7.

33 Ware JE. The status of health assessment 1994. Annu Rev Public Health 1995;16:327-54.

34 Hedback B, Perk J, Wodlin P. Long-term reduction of cardiac mortality after myocardial infarction: 10-year results of a comprehensive rehabilitation programme. Eur Heart f 1993;14:831-5.

35 Hasdai D, Garratt KN, Grill DE, et al. Effect of smoking status on the long-term outcome after successful percutaneous coronary revascularization. N Engl f Med 1997;336: 755-61.

36 Walter PJ. Return to work after coronary artery bypass surgery. Eur Heart $\mathcal{F}$ 1988;9(suppl L):58-66. 